\title{
Stability and activity of platinum nanoparticles in the oxygen electroreduction reaction: is size or uniformity of primary importance?
}

\author{
Kirill O. Paperzh ${ }^{1,2}$, Anastasia A. Alekseenko ${ }^{1}$, Vadim A. Volochaev³, llya V. Pankov ${ }^{3}$, \\ Olga A. Safronenko ${ }^{1}$ and Vladimir E. Guterman ${ }^{*} 1, \S$
}

\author{
Full Research Paper \\ Address: \\ ${ }^{1}$ Southern Federal University, Faculty of Chemistry, 344090, Zorge st. \\ 7, Rostov-on-Don, Russia, ${ }^{2}$ Prometheus R\&D LLC, 344091, 4g/36 \\ Zhmaylova st., Rostov-on-Don, Russia and ${ }^{3}$ Southern Federal \\ University, "High-Resolution Transmission Electron Microscopy" \\ Shared Use Center, 344090, 194/2 Stachki st., Rostov-on-Don, \\ Russia \\ Email: \\ Vladimir E. Guterman* - gut57@mail.ru \\ * Corresponding author \\ § Email: guter@sfedu.ru \\ Keywords: \\ durability; electrocatalysts; morphology control; oxygen reduction \\ reaction; platinum nanoparticles; size distribution; spatial distribution
}

Beilstein J. Nanotechnol. 2021, 12, 593-606. https://doi.org/10.3762/bjnano.12.49

Received: 19 March 2021

Accepted: 16 June 2021

Published: 29 June 2021

Associate Editor: W.-J. Ong

(C) 2021 Paperzh et al.; licensee Beilstein-Institut. License and terms: see end of document.

\begin{abstract}
Platinum-carbon catalysts are widely used in the manufacturing of proton-exchange membrane fuel cells. Increasing Pt/C activity and stability is an urgent task and the optimization of their structure seems to be one of the possible solutions. In the present paper, $\mathrm{Pt} / \mathrm{C}$ electrocatalysts containing small (2-2.6 nm) nanoparticles (NPs) of a similar size, uniformly distributed over the surface of a carbon support, were obtained by the original method of liquid-phase synthesis. A comparative study of the structural characteristics, catalytic activity in the oxygen electroreduction reaction (ORR), and durability of the synthesized catalysts, as well as their commercial analogs, was carried out. It was shown that the uniformity of the structural and morphological characteristics of Pt/C catalysts makes it possible to reduce the negative effect of the small size of NPs on their stability. As a result, the obtained catalysts were significantly superior to their commercial analogs regarding ORR activity, but not inferior to them in terms of stability.
\end{abstract}

\section{Introduction}

Nowadays, low-temperature proton-exchange membrane fuel cells (PEMFC) are gaining a wider application. This is due to their environmental friendliness, low operating temperature, and high adaptability of specific characteristics [1-3]. The key components of PEMFC membrane-electrode assemblies (MEA) are the proton-exchange polymer membrane and porous electrode layers, in which current-forming reactions of oxygen electroreduction (ORR) and hydrogen oxidation or an organic reducing agent oxidation (e.g. methanol) occur [4,5]. The need to carry out high-rate electrode reactions requires electrocatalysts (i.e., 
platinum nanoparticles - NPs - or its alloys), deposited mainly onto nano/microparticles of carbon supports, which are currently the best choice [6-8]. The most important functional characteristics of the catalytic layers are their activity in the corresponding reactions and stability, which reflects the ability to maintain its activity during operation. These characteristics depend on the PEMFC operating conditions, the composition and structure of the catalytic layers, and the catalysts themselves [9].

Platinum-carbon catalysts, whose composition and structure determine their functional characteristics, are the key components of MEA catalytic layers. Of particular importance is the study of the catalyst electrochemical behavior in the ORR, since it is at the cathode that strong polarization and pronounced degradation of the catalyst take place. Such a degradation occurs as a result of both the operation at high anodic potentials and the effect of aggressive oxygen-containing intermediates, which are formed during the multistage oxygen electroreduction reaction. When comparing platinum catalysts based on the same carbon support, differences in their electrochemical behavior are determined by the difference in the composition ( $\mathrm{Pt}$ loading in $\mathrm{Pt} / \mathrm{C}$ ), structure (shape and size of the platinum NPs, dispersion of their size, and features of spatial distributions), and the adhesion strength of NPs to the support [10]. The latter is likely to depend on the method/conditions of the synthesis [11].

The number of publications related to the effect of the structure of $\mathrm{Pt} / \mathrm{C}$ catalysts on their activity, primarily in ORR, is rather large. Nevertheless, more and more new papers, specifying the peculiarities of such influence, are being published every year. Initially, most researchers were inclined to believe that a decrease in the size of the nanoparticles is accompanied by a significant decrease in the platinum-specific surface activity. K. Kinoshita was one of the first researchers to obtain such results [12]. As a first approximation, the specific activity of platinum in the catalyst, being referred to the unit mass of the metal $I_{\text {mass }}$ (mass activity), is determined as a product of the electrochemically active surface area (ESA) and the specific activity $\left(I_{\mathrm{sp}}\right)$ of platinum:

$$
I_{\text {mass }}=\mathrm{ESA} \cdot I_{\mathrm{sp}}
$$

It was found that with the increase in the ESA, the ORR mass activity of $\mathrm{Pt} / \mathrm{C}$ passed through a flat maximum in the ESA values in the range of $60-90 \mathrm{~m}^{2} \cdot \mathrm{g}^{-1}(\mathrm{Pt})$, which was explained by the inverse dependence of each factor in Equation 1 on the size of platinum NPs [13]. Later, it was shown that the effect of the platinum NP size on the specific surface activity was much weaker than it seemed to be at first. For example, according to the results presented in [14], with a decrease in the average size of platinum nanoparticles (i.e., from 5-6 to 1-2 nm) the specific ORR activity of $\mathrm{Pt} / \mathrm{C}$ decreased no more than two times. In this case, an increase in ESA due to a decrease in the NP size can prevail over a decrease in $I_{\mathrm{sp}}$ and, according to Equation 1, leads to an increase in the mass activity of $\mathrm{Pt} / \mathrm{C}$ catalysts containing ultra-small platinum NPs. For example, in $[15,16]$ the authors succeeded in obtaining $\mathrm{Pt} / \mathrm{C}$ electrocatalysts based on ultra-small platinum NPs, which demonstrates a higher ORR mass activity in comparison with widespread commercial Pt/C analogs. In fact, different sites of NP surfaces have different specific activities in the ORR [17]. As a result, the control of the NP shape, leading to an increase in the proportion of more active areas, can lead to a significant increase in the Pt/C activity [18]. Moreover, according to the calculations in [17], NPs of each size can have its own optimal shape, which provides the highest ORR mass activity. Nevertheless, it is important to take into account that real $\mathrm{Pt} / \mathrm{C}$ catalysts contain nanoparticles of different sizes. To have the control over the size of the particles can cause the change in their shape, which in turn can result in the formation of a maximum on the curves of activity dependence on the average NP size [19].

The effect of Pt/C catalysts structure on durability has been less studied than the effect on the ORR activity. To assess the stability of the catalysts, much longer tests to evaluate their activity are required. Moreover, the correlation between the results of evaluating catalyst durability obtained during accelerated stress tests and the use of fuel cells in real practice is far from being perfect. Therefore, along with the study of how certain factors influence on the catalyst stability, the search for optimal methods and conditions for stress tests in an electrochemical cell is still progress. The degradation of electrocatalysts is a highly complex process and it can proceed in accordance with different mechanisms [9]. It has been established that the regression of $\mathrm{Pt} / \mathrm{C}$ functional characteristics can be associated with different reasons, including the dissolution of small platinum NPs (less than $3 \mathrm{~nm}$ in size) [14,20], reprecipitation of platinum from small NPs into larger ones [14,21,22], agglomeration of NPs in the process of their surface diffusion $[9,22]$, and NP shape change $[4,23]$. This can happen due to the oxidation of the carbon carrier, which causes the detachment of platinum NPs and loss of contact with the support [24-26], as well as the isolation of particles by adsorbed carbon monoxide released due to carbon oxidation [27-30]. Each of the mechanisms previously described can play a greater or smaller role, depending on the conditions of the catalysts tested and the features of their composition and structure [31].

When the same support is used, the stability of $\mathrm{Pt} / \mathrm{C}$ catalysts during their operation is affected primarily by the mass fraction of the metal and the size of the nanoparticles [32,33]. The cata- 
lyst stability, as a rule, increases with increasing NP size [14,22,32-36]. The probability of agglomeration and coalescence of NPs during a stress test also decreases with an increase in the average distance between platinum NPs in catalysts, which results in an increase of their stability [14]. Apparently, a relatively high stability of small-sized systems is possible when the platinum NPs are similar in size and their distribution is uniform over the surface of the carbon support [35,37-40]. For example, as it is shown in [40], the growth of the nanoparticles during the catalyst operation accelerates when large and small NPs are localized in the same regions of the support surface, and it slows down if the catalytic layer is formed from an ordinary mixture of two catalysts with small and large nanoparticles, respectively.

The need to reduce the content of expensive platinum in the catalysts forces the researchers to follow the path of reducing the size of NPs. However, the opposite effect of the NP size on the specific activity, stability, and ESA of the catalysts forces us to seek a compromise or, in other words, to seek structures with an optimal combination of catalyst mass activity and stability. In this regard, of particular interest are the methods for the synthesis of catalysts, which make it possible to obtain materials that combine small size of the nanoparticles, their narrow dimensional and uniform spatial distribution over the surface, and pores of support.

This study was based on the hypothesis that $\mathrm{Pt} / \mathrm{C}$ catalysts containing small nanoparticles, which are similar in size and uniformly distributed over the surface of a carbon support, can be both more active and more stable than catalysts based on larger particles, but with less uniformity of dimensional and spatial distribution.

Thus, the aim of this study was to obtain Pt/C catalysts containing small NPs narrow in size and with uniform spatial distributions and to compare the ORR activity and stability of the obtained catalysts and conventional analogs containing NPs of a larger size, but with less uniform structural characteristics. Taking into account the above requirement, we chose commercial catalysts that are widely used both in research and in the manufacture of fuel cells.

\section{Experimental Materials}

The synthesis of $\mathrm{Pt} / \mathrm{C}$ catalysts was carried out in the liquid phase according to the procedure described in detail in [16]. Formaldehyde was used as a reducing agent and the synthesis was carried out in an atmosphere of carbon monoxide. A weighed portion of a Vulcan XC-72 carbon support (Cabot Corporation) weighing from $0.150 \mathrm{~g}$ (when obtaining the material G40) to $0.055 \mathrm{~g}$ (when obtaining the material G20) was introduced into $18 \mathrm{~mL}$ of ethylene glycol, homogenized by ultrasound for $10 \mathrm{~min}$, and then stirred on a magnetic stirrer for $15 \mathrm{~min}$. Then, without stopping stirring, a water solution of $\mathrm{H}_{2} \mathrm{PtCl}_{6}$ (TU 2612-034-00205067-2003, Pt mass fraction of $37.6 \%$, Aurat, Russia) was introduced into the suspension and the $\mathrm{pH}$ was adjusted to 10 by adding a $0.5 \mathrm{M} \mathrm{KOH}$ solution (JSC Vekton, Russia). Then, $1 \mathrm{~mL}$ of formaldehyde (37\%, JSC Vekton, Russia) was added and the suspension was purged with carbon monoxide for $15 \mathrm{~min}$. Then, without stopping the $\mathrm{CO}$ blowing, the reaction mixture temperature was increased to $90{ }^{\circ} \mathrm{C}$ and the mixture was kept under constant stirring for $2 \mathrm{~h}$. The composition of the obtained catalysts is given in Table 1 . The numbers in the names of the samples correspond to the calculated platinum mass fraction in $\mathrm{Pt} / \mathrm{C}$.

Commercial Pt/C catalysts JM20 and JM40 (HiSPEC3000, 20 wt \% Pt; HiSPEC4000, 40 wt \% Pt, Johnson Matthey) were used as reference samples.

\section{Methods to verify the composition and structure of $\mathrm{Pt} / \mathrm{C}$ materials}

The Pt loading in the studied samples was determined by gravimetry. Ceramic crucibles were calcined to get a constant weight at $800-850{ }^{\circ} \mathrm{C}$. Next, they were weighed after complete

\begin{tabular}{|c|c|c|c|c|c|c|}
\hline \multirow[t]{2}{*}{ sample } & \multicolumn{2}{|c|}{ Pt loading in $\mathrm{Pt} / \mathrm{C}, \omega(\mathrm{Pt})$, wt \% } & \multirow{2}{*}{$\begin{array}{l}\text { average crystallite } \\
\text { diameter, } D_{\mathrm{Av}}, \mathrm{nm} \\
(\mathrm{XRD})\end{array}$} & \multirow{2}{*}{$\begin{array}{l}\text { average NP } \\
\text { size, } D_{N P}, n m \\
(T E M)\end{array}$} & \multirow{2}{*}{$\begin{array}{l}\text { specific number of } \\
\text { NPs, N, } 10^{15} \mathrm{~m}^{-2}\end{array}$} & \multirow{2}{*}{$\begin{array}{l}\text { average distance } \\
\text { between NPs, } \lambda, n m\end{array}$} \\
\hline & theoretical & actual & & & & \\
\hline G20 & 20 & $20.4 \pm 0.6$ & $1.2 \pm 0.1$ & $2.0 \pm 0.1$ & 9.6 & 8.0 \\
\hline G25 & 25 & $24.7 \pm 0.7$ & $1.2 \pm 0.1$ & $2.2 \pm 0.1$ & 9.9 & 7.7 \\
\hline G30 & 30 & $30.9 \pm 0.9$ & $1.3 \pm 0.1$ & $2.5 \pm 0.1$ & 10.1 & 7.4 \\
\hline G35 & 35 & $34.0 \pm 1.0$ & $1.3 \pm 0.1$ & $2.6 \pm 0.1$ & 10.4 & 7.2 \\
\hline G40 & 40 & $39.0 \pm 1.2$ & $1.3 \pm 0.1$ & $2.6 \pm 0.1$ & 13.0 & 6.2 \\
\hline JM20 & - & $20.0 \pm 0.6$ & $2.5 \pm 0.1$ & $2.7 \pm 0.1$ & 4.5 & 12.2 \\
\hline JM40 & - & $40.0 \pm 1.2$ & $3.7 \pm 0.1$ & $3.7 \pm 0.2$ & 5.5 & 9.9 \\
\hline
\end{tabular}


cooling. Then, approx. $0.02 \mathrm{~g}$ of the $\mathrm{Pt} / \mathrm{C}$ material was placed in crucibles and kept in a muffle furnace at $800-850{ }^{\circ} \mathrm{C}$ for $40 \mathrm{~min}$. Crucibles with a non-combustible residue $(\mathrm{Pt})$ were weighed after complete cooling. The difference in weight was used to determine the metal content in the sample.

To study the structural characteristics of the obtained Pt/C materials, we used the powder diffraction method. An ARL X'TRA powder diffractometer with a Bragg-Brentano geometry $(\theta-\theta), \mathrm{Cu} K \alpha$ radiation $(\lambda=0.154056 \mathrm{~nm})$ at room temperature, was used to record X-ray diffraction patterns. The X-ray diffraction patterns of the samples under study were recorded in the angle range of $5 \leq 2 \theta \leq 90$ degrees by the step-by-step scanning method with a detector movement step of 0.02 degrees. The X-ray diffraction patterns were processed by using the SciDavis software to properly extract the parameters of the peaks and this was of particular significance when they overlapped in the case of small-sized particles. The average platinum crystallite size $D_{\mathrm{Av}}$ was calculated using the Scherrer equation, as described in more detail in Supporting Information File 1.

The size of the platinum nanoparticles, the features related to their size, and the spatial distributions were also studied by transmission electron microscopy (TEM). The TEM images were obtained using a JEOL JEM F200 microscope (voltage $200 \mathrm{kV}$, current $12-15 \mu \mathrm{A}, \mathrm{CFEG})$. To prepare a sample for measurements, $0.5 \mathrm{mg}$ of the catalyst was placed into $1 \mathrm{~mL}$ of isopropanol and dispersed by ultrasound for $10 \mathrm{~min}$. A drop of the resulting suspension was applied to a standard copper mesh with a diameter of $3.05 \mathrm{~mm}$, covered with a 5-6 nm thick layer of amorphous carbon. Next, the sample was dried in air at room temperature for $60 \mathrm{~min}$. The histograms of platinum nanoparticle size distribution in the catalysts were plotted to determine the size of at least 400 randomly selected particles in the TEM images in different regions of the sample.

\section{Electrochemical investigation}

Electrochemical measurements were performed in a three-electrode cell on a VersaSTAT3 potentiostat using a rotating disk electrode (RDE) (Pine Research Instruments, USA). A saturated silver chloride electrode was used as a reference electrode. The potentials were given with regard to a reversible hydrogen electrode (RHE).

A thin, porous catalyst layer was applied to the electrode using the so-called "catalytic ink". To obtain a suspension of $\mathrm{Pt} / \mathrm{C}$ catalysts (i.e., "catalytic ink"), $900 \mu \mathrm{L}$ of isopropyl alcohol and $100 \mu \mathrm{L}$ of a $0.5 \%$ aqueous emulsion of Nafion ${ }^{\circledR}$ polymer were added to $6 \mathrm{mg}$ of each sample. Then, the suspension was dispersed with ultrasound for $15 \mathrm{~min}$. Under continuous stirring, an aliquot of "ink" of $6 \mu \mathrm{L}$ in volume was taken with a microdispenser and applied to the end of a polished and degreased glassy carbon disk with an area of $0.196 \mathrm{~cm}^{2}$, the exact weight of the drop was recorded. The electrode was dried in air for $20 \mathrm{~min}$ while rotating at $700 \mathrm{rpm}$.

Prior to measuring the ESA of the catalyst, the electrolyte was saturated with argon for $40 \mathrm{~min}$. Then, 100 cycles were carried out in the potential range from 0.04 to $1.2 \mathrm{~V}$ relative to RHE. The potential sweep speed was $200 \mathrm{mV} \cdot \mathrm{s}^{-1}$.

The electrochemically active surface area was determined from the cyclic voltammogram (CV) by calculating the amount of electricity consumed for desorption $\left(Q_{\mathrm{d}}\right)$ and adsorption $\left(Q_{\mathrm{ad}}\right)$ of atomic hydrogen, as described in more detail in Supporting Information File 1 . The $\mathrm{CV}$ recording rate was $20 \mathrm{mV} \cdot \mathrm{s}^{-1}$ and the potential range was $0.04-1.2 \mathrm{~V}$ relative to RHE.

To determine the ORR activity of the catalysts, the electrolyte was saturated with oxygen for $1 \mathrm{~h}$, after which a series of voltammograms was measured in the range of $0.12-1.19 \mathrm{~V}$ with a linear potential sweep at a rate of $20 \mathrm{mV} \cdot \mathrm{s}^{-1}$ at an electrode rotation speed values of $400,900,1600$, and $2500 \mathrm{rpm}$. The values of mass $\left(I_{\text {mass }}\right)$ and specific activity $\left(I_{\mathrm{sp}}\right)$ were calculated for a potential of $0.90 \mathrm{~V}$ (RHE)

The method of multiple voltammetric cycling in the potential range of $0.6-1.0 \mathrm{~V}$ (RHE) with a sweep rate of $100 \mathrm{mV} \cdot \mathrm{s}^{-1}$ was chosen as a method for assessing the degree of degradation of the electrocatalysts. The cycling was carried out in a $0.1 \mathrm{M}$ $\mathrm{HClO}_{4}$ solution saturated with argon at $25{ }^{\circ} \mathrm{C}$ for 5000 cycles. After every 500 cycles, two $\mathrm{CVs}$ were recorded at a potential sweep rate of $20 \mathrm{mV} \cdot \mathrm{s}^{-1}$ in the potential range of $0.04-1.2 \mathrm{~V}$, with respect to RHE, to calculate the ESA, as described previously. A detailed calculation of the catalyst stability is given in Supporting Information File 1.

\section{Results and Discussion}

The X-ray diffraction patterns of the catalysts that we have synthesized and the commercial analogs with different platinum contents have a similar shape, typical for $\mathrm{Pt} / \mathrm{C}$ materials (Figure 1). The presence of nanosized platinum crystallites causes a broadening of the characteristic maxima of platinum. The broadening increases with a decrease in the $D_{\mathrm{Av}}$. The results of calculating the $D_{\mathrm{Av}}$ values according to the Scherrer equation are shown in Table 1.

The mass fraction of platinum in the obtained materials ranged from 20.4 (G20) to $39 \mathrm{wt} \%$ (G40). The average crystallite size in the catalysts ranged from 1.2 (samples G20 and G25) to $1.3 \mathrm{~nm}$ (G30, G35, and G40) (Table 2). A selective electron 


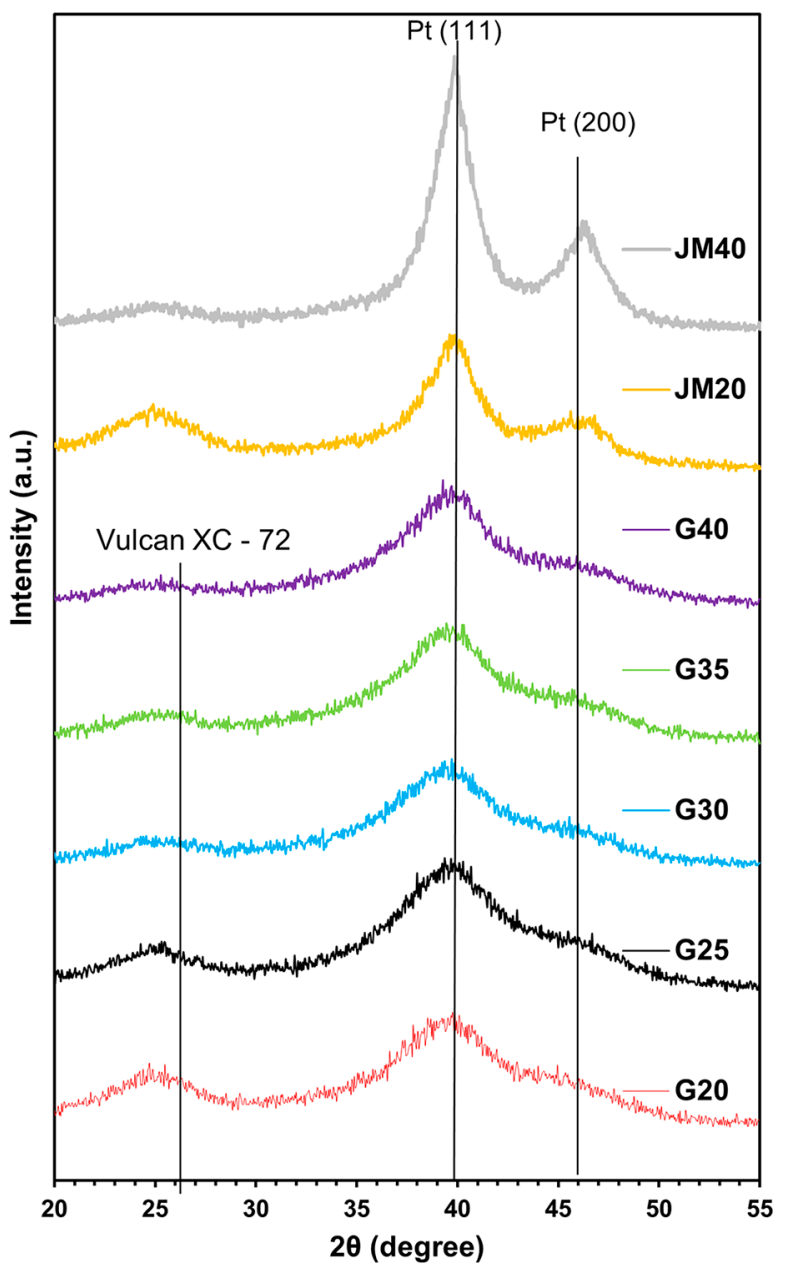

Figure 1: X-ray diffraction patterns of $\mathrm{Pt} / \mathrm{C}$ materials.

microscopy study of the synthesized materials (Figure 2) showed that with an increase in the Pt loading in the catalysts, the average nanoparticle size also increased from 2 (G20) to $2.6 \mathrm{~nm}(\mathrm{G} 30-\mathrm{G} 40)$.
The difference in the sizes of nanoparticles (crystallites) determined from the results of X-ray diffractometry and TEM is typical for nanostructured $\mathrm{Pt} / \mathrm{C}$ materials. It is due to several factors: some nanoparticles can consist of several crystallites, so they have a larger size [19]; differences in the principles of calculation, which serve as the basis for the corresponding research methods [41]; a possible contribution of NP structural defects to the broadening of the X-ray diffraction pattern maxima [42], and problems related to the recognition of ultrasmall particles in TEM micrographs. The composition of the commercial catalysts JM20 and JM40 is similar to that of G20 and G40: the average crystallite size is 2.5 and $3.7 \mathrm{~nm}$, and the average NP size is 2.7 and $3.7 \mathrm{~nm}$, respectively. The comparison of the NP size distribution histograms indicates that in the synthesized $\mathrm{Pt} / \mathrm{C}$ catalysts the smaller size of NPs is combined with their size distribution, which is narrower than that in the commercial reference samples (Figure 2). For example, in the sample G20, 92\% of NPs have a size of $2.0 \pm 0.5 \mathrm{~nm}$, while in the commercial analog JM20 they have the size of $2.75 \pm 0.75 \mathrm{~nm}$ (Figure 3). A similar difference is observed when we compared G40 and the JM40 analog (Figure 2).

We estimated the uniformity of the spatial NP distribution over the support surface. To this end, for each $\mathrm{Pt} / \mathrm{M}$ material in the TEM micrographs, we calculated the fraction of NPs that were not in contact (non-overlapping) with other NPs or in contact with one, two, or three other NPs. In this case, with the assumption that the smaller the number of intersections of NP images in the micrographs, the more uniformly distributed over the carrier surface the NPs. The disadvantages of such a simplified system used for analyzing the uniformity of the distribution are: i) the need to analyze the structure of a three-dimensional object from its two-dimensional image, and ii) the consideration of intersections, in the case when NPs are located on the lower and upper parts of the carbon particle but only their images overlap. Nevertheless, even such a comparison proves to be useful, especially in the case of comparing $\mathrm{Pt} / \mathrm{C}$ materials with a similar specific number of nanoparticles per unit of surface. The

Table 2: Parameters characterizing the electrochemical behavior of $\mathrm{Pt} / \mathrm{C}$ catalysts.

\begin{tabular}{|c|c|c|c|c|c|}
\hline sample & $\mathrm{ESA}, \mathrm{m}^{2} \cdot \mathrm{g}^{-1}(\mathrm{Pt})$ & $E_{1 / 2}, \mathrm{~V}($ at $1600 \mathrm{rpm})$ & number of ē & $I_{\text {mass }}, A \cdot g^{-1}(\mathrm{Pt})$ & $I_{\mathrm{sp}}, \mathrm{A} \cdot \mathrm{m}^{-2}(\mathrm{Pt})$ \\
\hline G20 & $120 \pm 12$ & 0.92 & 3.8 & 250 & 2.1 \\
\hline G25 & $116 \pm 12$ & 0.93 & 4.1 & 220 & 1.9 \\
\hline G30 & $98 \pm 10$ & 0.92 & 4.1 & 208 & 2.1 \\
\hline G35 & $93 \pm 9$ & 0.92 & 3.9 & 194 & 2.1 \\
\hline G40 & $88 \pm 9$ & 0.94 & 4.0 & 186 & 2.1 \\
\hline JM20 & $84 \pm 8$ & 0.91 & 3.9 & 182 & 2.2 \\
\hline JM40 & $65 \pm 7$ & 0.92 & 4.0 & 122 & 1.9 \\
\hline
\end{tabular}



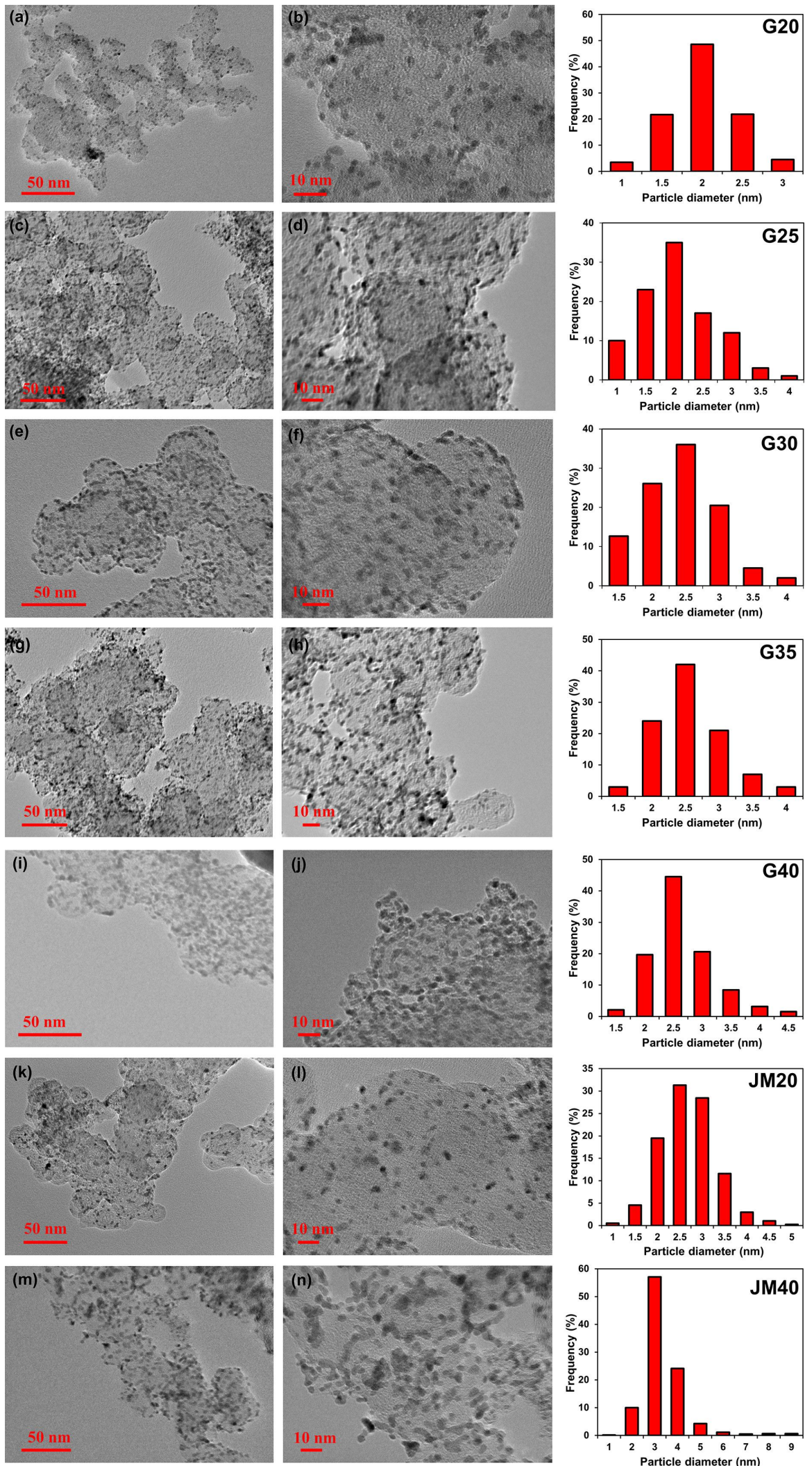

Figure 2: Micrographs of Pt/C samples of the catalysts G20 (a,b), G25 (c,d), G30 (e,f), G35 (g,h), G40 (l,j), JM20 (k,l), and JM40 (m,n), and histograms of nanoparticle size distribution in the corresponding materials. 

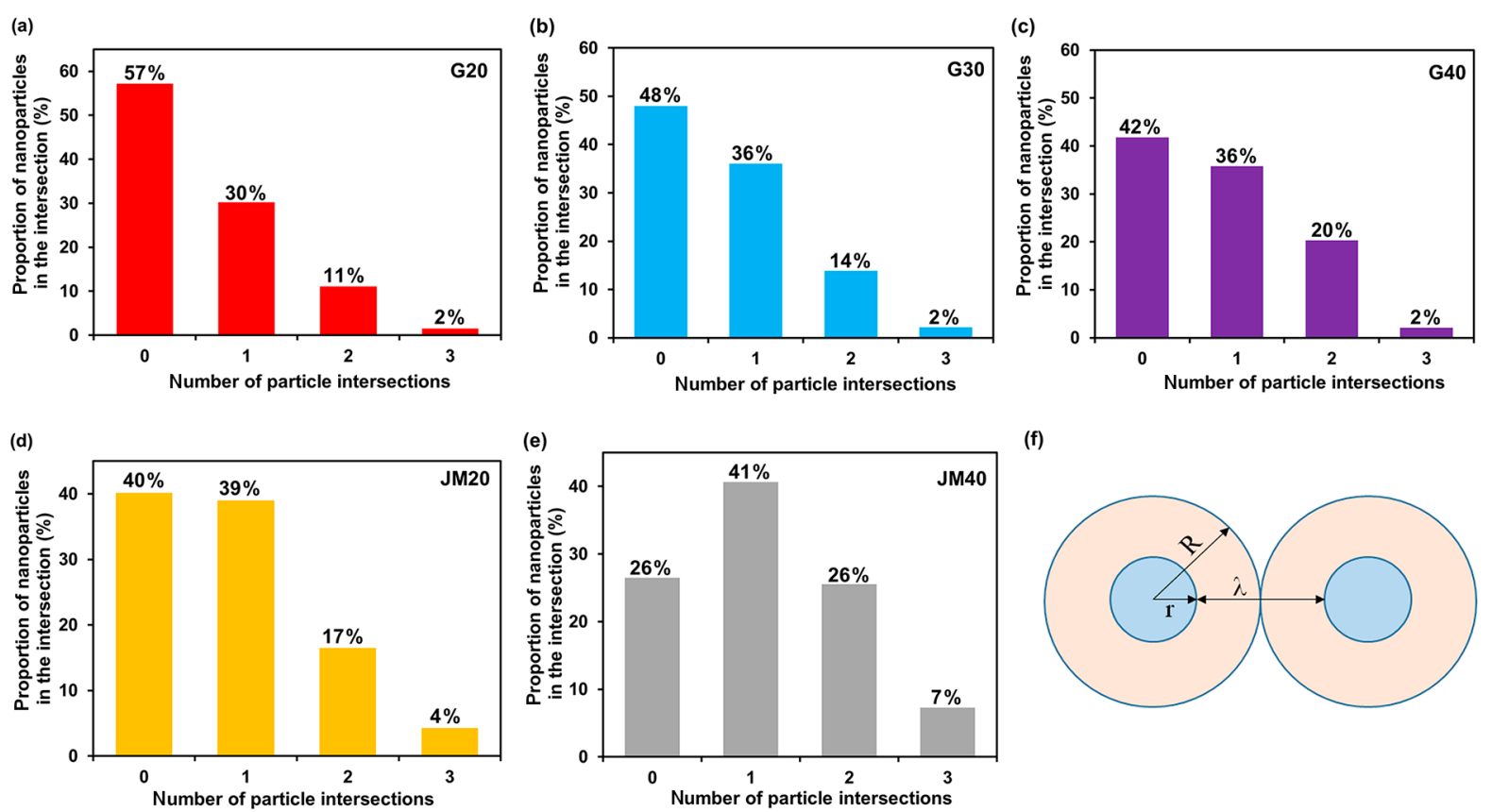

Figure 3: Histograms of nanoparticle distribution by the number of intersections with "neighbors" (a-e) and a schematic representation of the location of spherical nanoparticles within the geometric model ( $f)$.

histograms of the NP distribution by the number of intersections for different samples are shown in Figure $3 \mathrm{a}-\mathrm{e}$.

In the samples with the measured NP size, the average distance between the nanoparticles was calculated using a simplified geometric model. It was assumed that spherical particles of the same size are uniformly distributed on the flat surface of the carrier. Within the framework of the model, one can describe the geometry of a NP distribution by surrounding them with a region of a certain radius $R$, its value depending on the radius $(r)$ of the NPs and the distance between them $(\lambda)$ (Figure $3 f$ ).

To determine the values of the parameters $R$ and $\lambda$, the number $N$ of nanoparticles per $1 \mathrm{~m}^{2}$ of the carbon support was calculated:

$$
N_{\mathrm{NP}}=\frac{m(\mathrm{Pt})}{m(\mathrm{NP}) \cdot S(\mathrm{C})},
$$

where $m(\mathrm{Pt})$ is the mass of platinum applied to $1 \mathrm{~g}$ of carbon support, $m(\mathrm{NP})$ is the mass of one spherical platinum particle $(\mathrm{g}), S(\mathrm{C})$ is the surface area of the carbon support $\left(\mathrm{m}^{2} \cdot \mathrm{g}^{-1}\right)$ equals to $250 \mathrm{~m}^{2} \cdot \mathrm{g}^{-1}$.

The mass of a spherical particle is determined by its size:

$$
m(\mathrm{NP})=\frac{4}{3} \pi r^{3} \rho
$$

where $\rho$ is the density of platinum $\left(21.45 \times 10^{6} \mathrm{~g} \cdot \mathrm{m}^{-3}\right)$. Equation 4 was used to calculate $R$ :

$$
R=\frac{0.5}{\sqrt{N(\mathrm{NPs})}}
$$

The average distance between nanoparticles $(\lambda)$ was calculated by Equation 5:

$$
\lambda=2(R-r)
$$

The results of the model calculation (Equations 2-5) of the NP specific number and the average distance between NPs for the studied catalysts are shown in Table 1 .

The characteristic analysis of the platinum NP spatial distribution was carried out in accordance with the results obtained by processing the TEM micrographs (Figure 2a-e). It indicates a greater uniformity of the spatial distribution of platinum NPs in the $\mathrm{G}$ series catalysts as compared to the JM20 and JM40 samples. For example, in the catalysts G20 and G40, 57\% and 42\% of NPs, respectively, are not adjacent to their "neighbors". At the same time, in the commercial samples of similar composition, JM20 and JM40, the proportion of NPs is only $40 \%$ and $26 \%$, respectively. The share of NPs that has one or more inter- 
sections with "neighbors" increases in the series: G20 (43\%) < G30 $(52 \%)<\mathrm{G} 40(58 \%) \leq \mathrm{JM} 20(60 \%)<\mathrm{JM} 40(74 \%)$. It is important that, due to the large average size and average mass of NPs in commercial samples, the specific number of such particles is somewhat smaller, and the average distance between NPs, calculated within the framework of a simplified model, is slightly larger than that for NPs in the catalysts G20, G30, and G40 (Table 1). This means that there are no geometric reasons that could cause a lower uniformity of the NP spatial distribution on the surface of a carbon support in commercial $\mathrm{Pt} / \mathrm{C}$ catalysts.

Thus, the original procedure used for the synthesis of $\mathrm{Pt} / \mathrm{C}$ catalysts made it possible to successfully solve the first of the tasks posed in this study: to obtain $\mathrm{Pt} / \mathrm{C}$ materials characterized by a smaller size of nanoparticles, narrower dimensional and more uniform spatial distribution over the surface of the Vulcan $\mathrm{XC}-72$ carbon support, as compared with the commercial electrocatalysts JM20 and JM40.

The cyclic voltammograms of $\mathrm{Pt} / \mathrm{C}$ catalysts have a characteristic form (Figure 4). As the content of platinum in the catalysts increases, the specific current values decrease in all sections of the CVs (Figure 4).

The calculation based on the amount of energy consumed for the electrochemical adsorption and desorption of an atomic hydrogen monolayer showed that an increase in the Pt loading in the obtained samples (from 20.4 to $39 \mathrm{wt} \%$ ) leads to a decrease in the ESA (from 120 to $88 \mathrm{~m}^{2} \cdot \mathrm{g}^{-1}(\mathrm{Pt}$ )) (Table 2), which is due to both an increase in the average size and in NP coalescence (Table 1, Figure 3).



Figure 4: Cyclic voltammograms of $\mathrm{Pt} / \mathrm{C}$ samples. Sweep rate of $20 \mathrm{mV} \cdot \mathrm{s}^{-1}$, 2nd cycle. Electrolyte used: $0.1 \mathrm{M} \mathrm{HClO}_{4}$ solution saturated with $\mathrm{Ar}$ at atmospheric pressure.

When comparing the synthesized and commercial catalysts of the same composition, one can see that the ESA of JM catalysts is lower than that of G catalysts (Table 2), which is due to the difference in their structural characteristics described above (Table 1). The commercial catalyst JM40 has the minimal ESA value (Table 2).

The study of the ORR kinetics, carried out by linear voltammetry using RDE (Figure 5), showed that the ORR proceeds according to the four-electron mechanism on all catalysts (Table 2). The values of the half-wave potential of oxygen electroreduction for the studied catalysts vary in the range from 0.91 (JM20) to $0.94 \mathrm{~V}$ (G40) (Table 2). Note that the values of the specific kinetic current of all catalysts are very close around
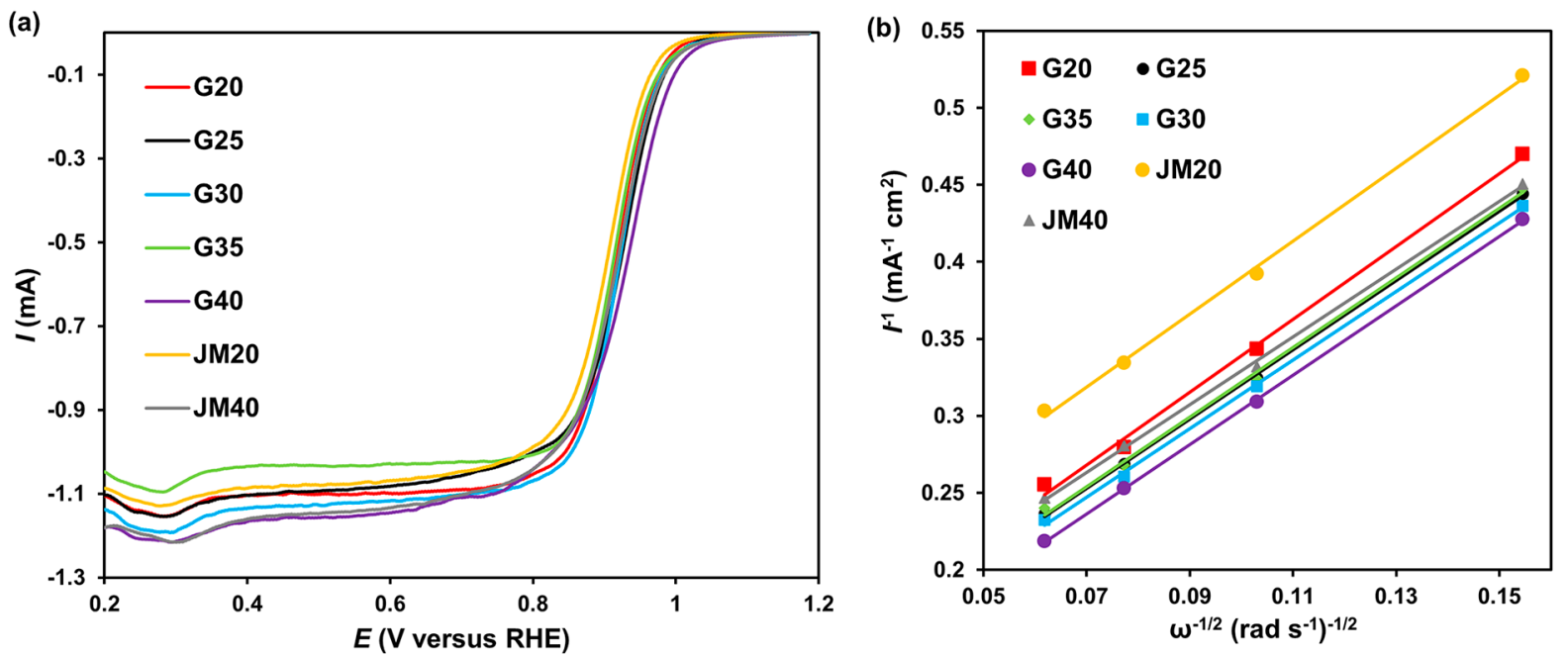

Figure 5: (a) Linear voltammograms of the ORR. The rotation speed of the disk is $1600 \mathrm{rpm}^{-1}$, (b) $j^{-1}-\omega^{-0.5}$ dependence at a potential of $0.90 \mathrm{~V}$. The rate of the potential sweep is $20 \mathrm{mV} \cdot \mathrm{s}^{-1}$. Electrolyte used: $0.1 \mathrm{M} \mathrm{HClO}_{4}$ solution saturated with $\mathrm{O}_{2}$ at atmospheric pressure. 
$2.05 \pm 0.15 \mathrm{~A} \cdot \mathrm{m}^{-2}(\mathrm{Pt})$ (Table 2 ). This suggests that a change in the size of the nanoparticles in the range from 2.0 to $3.1 \mathrm{~nm}$ does not affect the specific activity of platinum in the ORR. The key factor that determines the mass activity of the catalysts under these conditions is the ESA. As the ESA increases in the series $\mathrm{G} 40<\mathrm{G} 35<\mathrm{G} 30<\mathrm{G} 25<\mathrm{G} 20$, the mass activity of the synthesized catalysts also increases (Table 2). Note that the mass activity of the sample G20 is almost 1.5 times higher than that of JM20, a commercial analog with a similar platinum content (Table 2).

During the stress test of the catalysts, a regular decrease in the current values occurs which is more pronounced in the oxygen region of the $\mathrm{CV}$ (Figure 6). Interestingly, the value of the relative stability of the G series catalysts was found to be the same, independent of either the mass fraction of platinum in the catalysts or the average NP size (Table 3). Despite the larger size of the platinum nanoparticles in the commercial catalysts, their relative stability turned out to be somewhat lower than that in the samples we synthesized. Apparently, the higher uniformity of the catalyst structure compensates for the negative effect of the smaller NP size on the process of their degradation. According to $[14,33]$, the decrease in ESA and activity of the catalysts during the cycling of the potential in the range of $0.6-1.0 \mathrm{~V}$ is largely due to the processes of platinum reprecipitation and coalescence of NPs.

The proximity of the sizes of the NPs and the uniformity of their distribution should slow down the course of these negative phenomena. As we have already noted, the positive role of proximity of the sizes of NPs located in adjacent regions of the catalyst, with regard to its stability, was demonstrated in [40].

Upon completion of the stress test, a decrease is observed in the specific activity of the catalysts in ORR, which is more pronounced for samples with a low platinum loading (i.e., JM20 and G20). This follows from the comparison of voltammograms (Figure 7), the values of the specific kinetic currents of
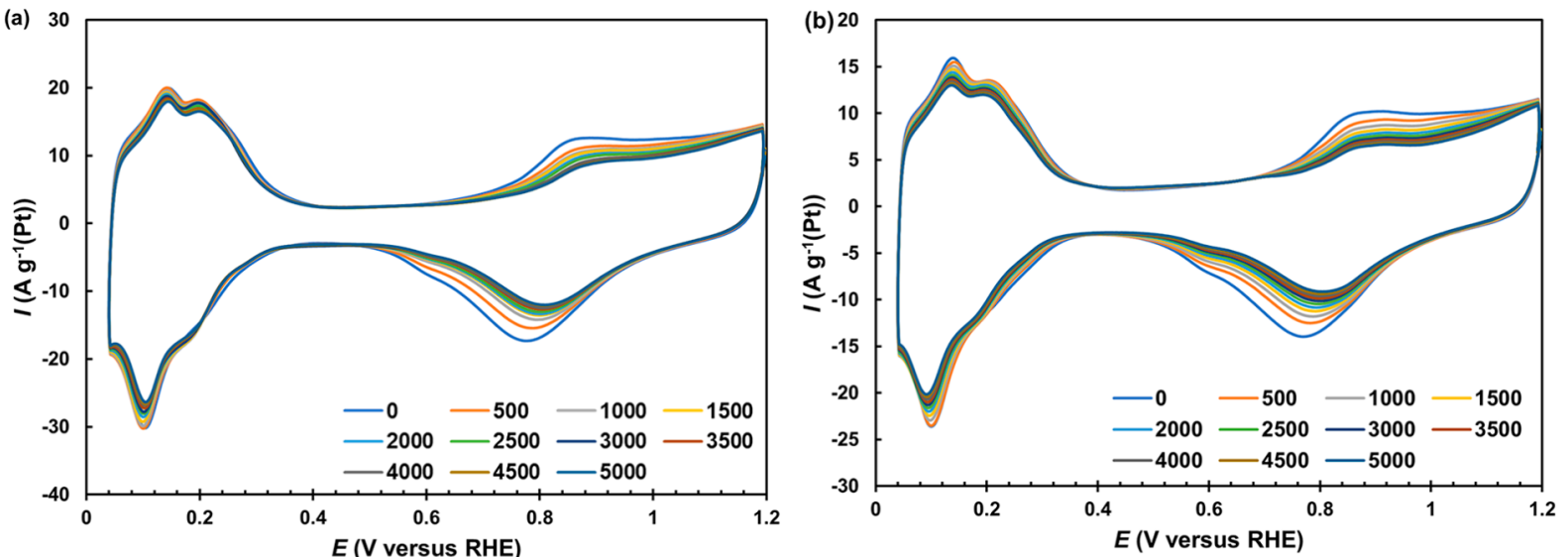

Figure 6: Cyclic voltammograms of (a) G40 and (b) JM40 catalysts measured at a potential sweep rate of $20 \mathrm{mV} \cdot \mathrm{s}^{-1}$ for every 500 stress test cycles. Electrolyte is $0.1 \mathrm{M} \mathrm{HClO}_{4}$, Ar atmosphere.

\begin{tabular}{|c|c|c|c|c|c|c|c|}
\hline \multirow[t]{2}{*}{ sample } & \multirow[t]{2}{*}{$\mathrm{ESA}_{5000}, \mathrm{~m}^{2} \cdot \mathrm{g}^{-1}$} & \multirow[t]{2}{*}{$\mathrm{ESA}_{5000} / \mathrm{ESA}_{0}, \%$} & \multirow[t]{2}{*}{ number ē } & \multicolumn{2}{|c|}{ electric current at $E=0.90 \mathrm{~V}$} & \multirow[t]{2}{*}{$E_{1 / 2}, \mathrm{~V}$} & \multirow{2}{*}{$I_{\text {mass }}^{5000} / I_{\text {mass }}^{0}, \%$} \\
\hline & & & & $I_{\text {mass }}, A \cdot g^{-1}(\mathrm{Pt})$ & $I_{\mathrm{sp}}, \mathrm{A} \cdot \mathrm{m}^{-2}(\mathrm{Pt})$ & & \\
\hline G20 & 103 & 86 & 3.9 & 118 & 1.2 & 0.89 & 47 \\
\hline G25 & 100 & 86 & 3.8 & 132 & 1.3 & 0.91 & 60 \\
\hline G30 & 84 & 86 & 3.7 & 155 & 1.8 & 0.92 & 75 \\
\hline G35 & 80 & 86 & 3.5 & 145 & 1.8 & 0.92 & 75 \\
\hline G40 & 76 & 86 & 4.2 & 130 & 1.7 & 0.93 & 70 \\
\hline JM20 & 69 & 82 & 4.3 & 60 & 0.9 & 0.88 & 33 \\
\hline JM40 & 55 & 82 & 3.6 & 83 & 1.5 & 0.90 & 69 \\
\hline
\end{tabular}


ORR on the studied catalysts before (Table 2), and after (Table 3) the completion of the stress test.

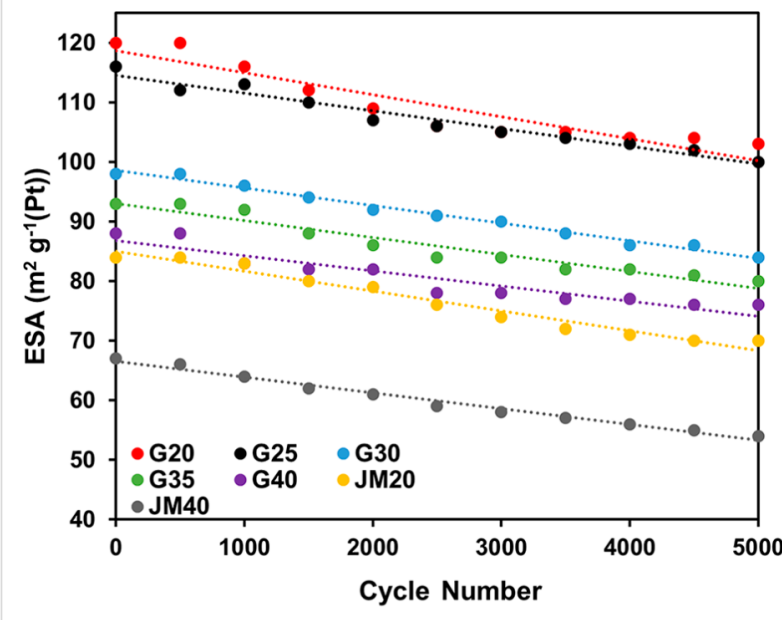

Figure 7: Dependence of the ESA of the catalysts on the number of stress test cycles.

The relationship between the ORR mass activity of the catalysts with specific activity and ESA can be expressed by Equation $6[36]$ :

$$
I_{\text {mass }}=\sum\left(I_{\mathrm{k}}^{\mathrm{sp}} \Theta_{\mathrm{k}}\right) \mathrm{ESA},
$$

where $I_{\mathrm{k}}^{\mathrm{sp}}$ is the specific activity of the NP surface areas (faces, edges) of the k-type, $\Theta_{\mathrm{k}}$ is the fraction of the nanoparticle surface belonging to the k-type areas. Taking into account platinum nanoparticles with different numbers of catalytically active sites on their surface (different types of faces, edges, vertices, steps) it can be assumed that the smaller the amount of platinum contained in the catalytic layer, the faster the decrease of the proportion of the most active sites during the stress test of the catalysts. Since the platinum NPs in the samples G20-G40 have a similar size, and the number of NPs in the catalytic layer increases with an increase in the platinum loading in the catalyst during the test, a much larger amount of oxygen is reduced in the catalyst G20 at each NP than that in the catalyst G40.

As a result, the reorganization of the NP structure accompanied by a decrease in the proportion of the most catalytically active faces is more pronounced in the G20 catalyst than in the G40 catalyst. At the same time, the total surface area of the NPs does not change very much because of the structural reorganization (Table 2 and Table 3), which one can see when the CVs, in their "hydrogen" region, before and after the stress test are compared (Figure 7). This determines the proximity of the relative stability values, calculated from the ESA ratio. Another reason for the platinum loading effect (the number of NPs in the catalytic layer) on the change in the catalyst activity may be the poisoning of active centers by the impurities contained in the solution and in the carbon support. Prior to the measurements, an identical amount (approx. $0.036 \mathrm{mg}$ ) of each catalyst was applied to the end of the disk electrode (see Experimental section). Taking into account the Pt loading in the catalysts and the corresponding ESA values (Table 1 and Table 2), it is easy to calculate that the ESA in the initially formed catalytic layers was approximately 8.8 for G20 and $12.4 \mathrm{~cm}^{2}$ for G40. With an identical quantity of impurities contained in the solution, the poisoning of the active centers should be more pronounced in catalyst G20 since a more significant decrease in the ORR specific activity is observed in that sample.

Upon completion of the stress test, the ORR mass activity of the catalysts increases in the following order: JM20 < JM40 < G20 $<\mathrm{G} 40 \leq \mathrm{G} 25<\mathrm{G} 35<\mathrm{G} 30$ (Table 3). The change in the form of the voltammograms before and after the stress test is clearly shown in Supporting Information File 1, Figure S4. A decrease in the value of $E_{1 / 2}$ is observed for all materials, but it is more pronounced for the samples G20 and JM20 and less pronounced for G30, G35, and G40 (Supporting Information File 1, Figure S4 and Table 3).

The samples G20 and JM20 subjected to stress tests were examined by TEM. During the stress test the average nanoparticle size in the sample G20 increased from 2.0 to $3.0 \mathrm{~nm}$, and in the sample JM20 it increased from 2.7 to $3.5 \mathrm{~nm}$ (Figure 8). The sample G20 also retained a narrower nanoparticle size distribution than that of JM20 (compare the histograms in Figure 8).

The proportion of nanoparticles overlapping with one, two, or three neighbors was $45 \%$ in the sample JM20 and 30\% in the sample G20 after the stress test (Figure 9).

Thus, even after the completion of the stress test, the sample G20 retained a more uniform morphology compared to the sample JM20. This result fully correlates with the results from the electrochemical behavior studies of the samples after the stress test.

Due to the changes in the structural characteristics of the catalysts, values of all three parameters in Equation 6 can change in a different way during the stress tests of each sample. This may be the reason for some change of the catalysts location in the row of increased mass activity, as compared to their location in the same row before the stress tests. Nevertheless, upon completion of the stress test, all the studied G series catalysts remained more active in the ORR compared to the commercial JM20 and JM40 catalysts. 

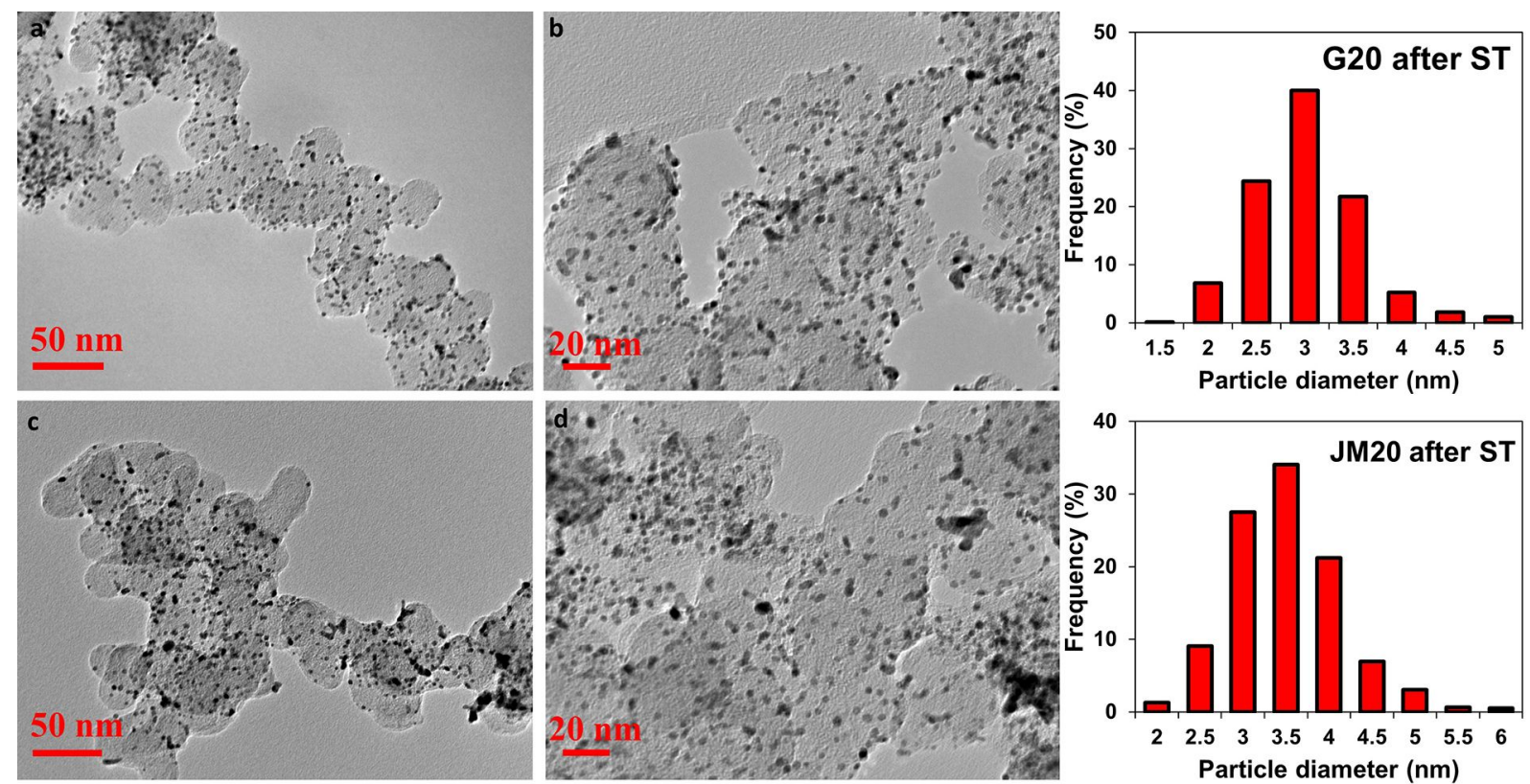

Figure 8: Micrographs of Pt/C samples of catalysts G20 (a,b) and JM20 (c,d) after stress test and histograms of nanoparticle size distribution of the corresponding materials.
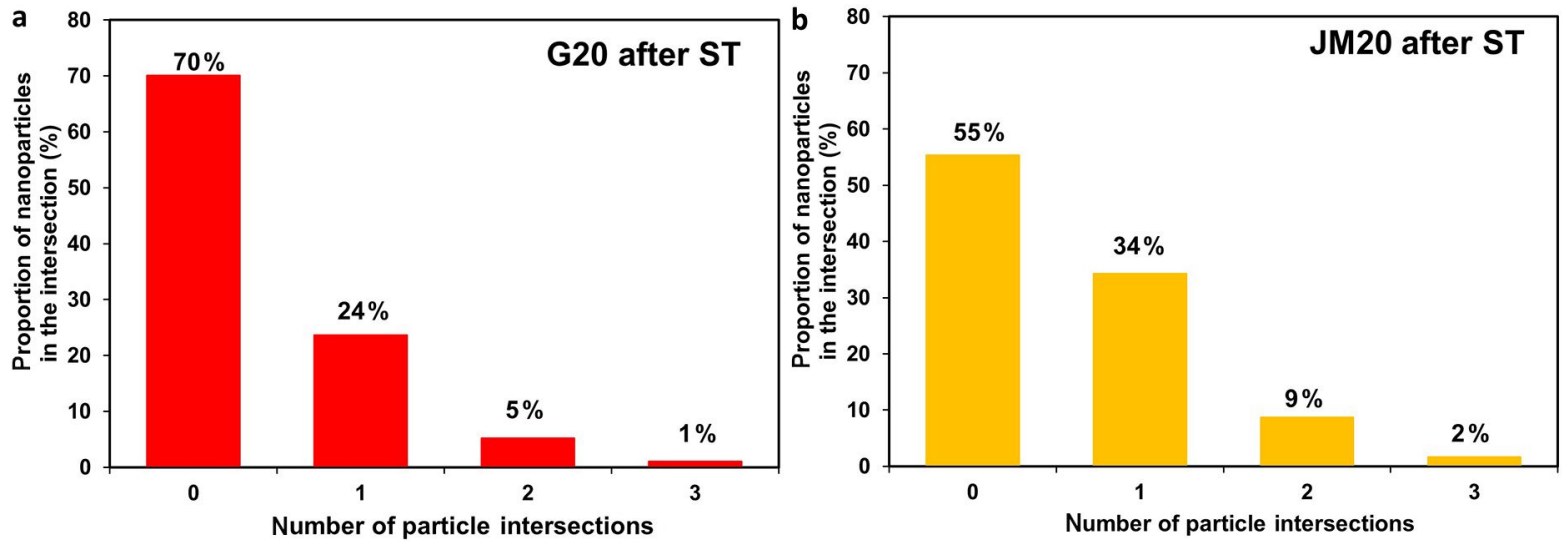

Figure 9: Histograms of nanoparticle distribution by the number of intersections with "neighbors" for the catalysts G20 (a) and JN20 (b) after the stress test.

The change in the ESA absolute values during the stress test, shown in Figure 7, is described by a linear dependence (see the correlation coefficients in Table 4). In the series of catalysts G20-G40 the rate of ESA reduction, calculated by the tangent of the slope formed by the straight lines, decreases with an increase in the Pt loading in the materials (Table 4). In this case, the values of the ESA rate decrease are very similar among catalysts with an identical Pt loading: G20 and JM20, G40 and GM40, respectively (Table 4). However, since the initial ESA for the catalysts G20 and G40 are significantly higher than that for JM20 and JM40, the synthesized catalysts G20 and G40 have a higher mass activity upon completion of the stress test than that of their commercial analogs JM20 and JM40.
Table 4: Coefficients of the slope angle formed by the straight line dependencies "ESA as a function of the cycle number" and the correlation parameters of the linear dependence equation.

$\begin{array}{lll}\text { sample } \omega(\mathrm{Pt}), \mathrm{wt} \% & -\mathrm{k} \times 10^{6}, & \text { correlation } \\ & \mathrm{m}^{2} \cdot \mathrm{g}^{-1}(\mathrm{Pt}) & \text { coefficient, } R^{2}\end{array}$

\begin{tabular}{llll}
\hline G20 & 20.4 & 3691 & 0.882 \\
G25 & 24.6 & 2982 & 0.959 \\
G30 & 30.9 & 2945 & 0.987 \\
G35 & 34.0 & 2855 & 0.938 \\
G40 & 39.0 & 2545 & 0.888 \\
JM20 & 20.0 & 3327 & 0.968 \\
JM40 & 40.0 & 2655 & 0.984
\end{tabular}




\section{Conclusion}

The Pt/C catalysts G20, G25, G30, G35, and G40 containing from 20 to $39 \mathrm{wt} \%$ of platinum with NPs of a small size (from 2 to $2.6 \mathrm{~nm}$ ), which demonstrated a narrow and uniform size and spatial distribution on the surface and in the pores of the carbon support Vulcan XC-72, were obtained by liquid-phase synthesis.

Due to the smaller size and higher uniformity of the NP spatial distribution, the $\mathrm{G}$ series catalysts are characterized by higher ESA values (from 120 to $88 \mathrm{~m}^{2} \cdot \mathrm{g}^{-1}(\mathrm{Pt})$ ) than the commercial $\mathrm{Pt} / \mathrm{C}$ catalysts JM20 and JM40 (Johnson Matthey) (84 and $\left.67 \mathrm{~m}^{2} \cdot \mathrm{g}^{-1}(\mathrm{Pt})\right)$, which contained 20 and $40 \mathrm{wt} \%$ of platinum, respectively. The ORR specific activity of all $\mathrm{Pt} / \mathrm{C}$ catalysts turned out to be approximately the same. However, due to higher ESA values, the mass activity of G20 and G40 significantly exceeded the mass activity of the corresponding commercial samples JM20 and JM40.

The degradation of the catalysts was studied with the help of a stress test protocol, used in the "soft" mode, in which voltammetric potential sweep cycles were performed in the range 0.6-1.0 V. It was shown that the ESA decrease of catalysts during 5000 stress test cycles is fairly well described by a linear regression equation. The rate of ESA decrease reduces, as the $\mathrm{Pt}$ loading in the catalysts increases; however, it is almost identical for the synthesized and commercial catalysts with a similar Pt loading - G20 and JM20, G40 and JM40, respectively. After the stress tests, the mass activity of the catalysts decreases less than the ESA. Apparently, the degradation of the catalysts is not only due to a decrease in the ESA, but also due to a decrease in the fraction of the nanocrystal surface, which belongs to the regions with the highest catalytic activity. At the same time, the mass activity of the $\mathrm{G}$ series catalysts exceeds the mass activity of the commercial analogs both before and after the stress tests.

The results of this study show that $\mathrm{Pt} / \mathrm{C}$ catalysts containing smaller nanoparticles can significantly exceed the catalysts based on larger nanoparticles in terms of ORR mass activity and they do not have an inferior stability. The reason for an unexpectedly high stability of catalysts containing small nanoparticles is most likely due to the uniformity of their structure, which manifests itself in the similarity of the nanoparticle sizes and uniformity of their distribution over the support surface. We have to admit that various methods for synthesizing $\mathrm{Pt} / \mathrm{C}$ can also have an effect on the surface of the carbon support and the strength of the platinum NPs adhesion to its surface. Thus, the positive effects of the structural uniformity can compensate for the size effect that has a negative influence on the NP stability.
It is important to note that at a similar degradation rate (ESA decrease during the stress test) the $\mathrm{Pt} / \mathrm{C}$ catalysts that we have synthesized demonstrated an ORR mass activity which exceeded the mass activity of the commercial $\mathrm{Pt} / \mathrm{C}$ analogs by approx. $30-60 \%$, both in the initial state and upon completion of the stress test.

\section{Supporting Information}

This file shows how the average platinum crystallite size $D_{\mathrm{Av}}$ is calculated based on the $\mathrm{X}$-ray diffraction pattern, how the electrochemically active surface area is obtained, how the catalytic activity is determined in the ORR, and the degradation degree of the electrocatalysts.

\section{Supporting Information File 1}

Experimental and theoretical methods used to obtain catalyst parameters.

[https://www.beilstein-journals.org/bjnano/content/ supplementary/2190-4286-12-49-S1.pdf]

\section{Funding}

This research was financially supported by the Ministry of Science and Higher Education of the Russian Federation (State assignment in the field of scientific activity No 0852-20200019).

\section{Acknowledgements}

The authors are grateful to Mr. Nikulin A.Yu. for assistance in the XRD pattern registration and to the "Shared Use Center High-Resolution Transmission Electron Microscopy" (SFedU) for conducting the TEM studies.

\section{ORCID ${ }^{\circledR}$ iDs}

Kirill O. Paperzh - https://orcid.org/0000-0003-4878-9728 Anastasia A. Alekseenko - https://orcid.org/0000-0001-7948-0948 Vadim A. Volochaev - https://orcid.org/0000-0003-2982-9974 llya V. Pankov - https://orcid.org/0000-0001-5302-4792 Olga A. Safronenko - https://orcid.org/0000-0003-2466-6651 Vladimir E. Guterman - https://orcid.org/0000-0003-0403-0074

\section{Preprint}

A non-peer-reviewed version of this article has been previously published as a preprint: https://doi.org/10.3762/bxiv.2021.27.v1

\section{References}

1. Qin, C.; Wang, J.; Yang, D.; Li, B.; Zhang, C. Catalysts 2016, 6, 197. doi:10.3390/catal6120197

2. O'Hayre, R. P. Fuel cell fundamentals, 2nd ed.; John Wiley \& Sons Limited: New York, USA, 2009. 
3. Kongkanand, A.; Mathias, M. F. J. Phys. Chem. Lett. 2016, 7, 1127-1137. doi:10.1021/acs.jpclett.6b00216

4. Katsounaros, I.; Cherevko, S.; Zeradjanin, A. R.; Mayrhofer, K. J. J. Angew. Chem., Int. Ed. 2014, 53, 102-121. doi:10.1002/anie.201306588

5. Chan, S.; Jankovic, J.; Susac, D.; Saha, M. S.; Tam, M.; Yang, H.; Ko, F. J. Mater. Sci. 2018, 53, 11633-11647. doi:10.1007/s10853-018-2411-4

6. Yaroslavtsev, A. B.; Dobrovolsky, Y. A.; Shaglaeva, N. S.; Frolova, L. A.; Gerasimova, E. V.; Sanginov, E. A. Russ. Chem. Rev. 2012, 81, 191-220. doi:10.1070/rc2012v081n03abeh004290

7. Litster, S.; McLean, G. J. Power Sources 2004, 130, 61-76. doi:10.1016/j.jpowsour.2003.12.055

8. Jung, N.; Chung, D. Y.; Ryu, J.; Yoo, S. J.; Sung, Y.-E. Nano Today 2014, 9, 433-456. doi:10.1016/j.nantod.2014.06.006

9. Borup, R.; Meyers, J.; Pivovar, B.; Kim, Y. S.; Mukundan, R.; Garland, N.; Myers, D.; Wilson, M.; Garzon, F.; Wood, D.; Zelenay, P.; More, K.; Stroh, K.; Zawodzinski, T.; Boncella, J.; McGrath, J. E.; Inaba, M.; Miyatake, K.; Hori, M.; Ota, K.; Ogumi, Z.; Miyata, S.; Nishikata, A.; Siroma, Z.; Uchimoto, Y.; Yasuda, K.; Kimijima, K.-i.; Iwashita, N. Chem. Rev. 2007, 107, 3904-3951. doi:10.1021/cr050182

10. Sui, S.; Wang, X.; Zhou, X.; Su, Y.; Riffat, S.; Liu, C.-j. J. Mater. Chem. A 2017, 5, 1808-1825. doi:10.1039/c6ta08580f

11. Dai, S.; Zhang, J.; Fu, Y.; Li, W. J. Mater. Sci. 2018, 53, 423-434. doi:10.1007/s10853-017-1508-5

12. Kinoshita, K. J. Electrochem. Soc. 1990, 137, 845-848. doi:10.1149/1.2086566

13. Gasteiger, H. A.; Kocha, S. S.; Sompalli, B.; Wagner, F. T. Appl. Catal., B 2005, 56, 9-35. doi:10.1016/j.apcatb.2004.06.021

14. Meier, J. C.; Galeano, C.; Katsounaros, I.; Witte, J.; Bongard, H. J.; Topalov, A. A.; Baldizzone, C.; Mezzavilla, S.; Schüth, F.; Mayrhofer, K. J. J. Beilstein J. Nanotechnol. 2014, 5, 44-67. doi:10.3762/bjnano.5.5

15. Garlyyev, B.; Kratzl, K.; Rück, M.; Michalička, J.; Fichtner, J.; Macak, J. M.; Kratky, T.; Günther, S.; Cokoja, M.; Bandarenka, A. S.; Gagliardi, A.; Fischer, R. A. Angew. Chem., Int. Ed. 2019, 58, 9596-9600. doi:10.1002/anie.201904492

16. Alekseenko, A. A.; Ashihina, E. A.; Shpanko, S. P.; Volochaev, V. A.; Safronenko, O. I.; Guterman, V. E. Appl. Catal., B 2018, 226, 608-615. doi:10.1016/j.apcatb.2018.01.013

17. Rossi, K.; Asara, G. G.; Baletto, F. ACS Catal. 2020, 10, 3911-3920. doi:10.1021/acscatal.9b05202

18. Hussain, S.; Erikson, H.; Kongi, N.; Sarapuu, A.; Solla-Gullón, J.; Maia, G.; Kannan, A. M.; Alonso-Vante, N.; Tammeveski, K. Int. J. Hydrogen Energy 2020, 45, 31775-31797. doi:10.1016/j.ijhydene.2020.08.215

19. Leontyev, I. N.; Belenov, S. V.; Guterman, V. E.; Haghi-Ashtiani, P.; Shaganov, A. P.; Dkhil, B. J. Phys. Chem. C 2011, 115, 5429-5434. doi:10.1021/jp1109477

20. Holby, E. F.; Sheng, W.; Shao-Horn, Y.; Morgan, D. Energy Environ. Sci. 2009, 2, 865-871. doi:10.1039/b821622n

21. Antolini, E.; Salgado, J. R. C.; Gonzalez, E. R. J. Power Sources 2006, 160, 957-968. doi:10.1016/j.jpowsour.2006.03.006

22. Cherevko, S.; Kulyk, N.; Mayrhofer, K. J. J. Nano Energy 2016, 29 , 275-298. doi:10.1016/j.nanoen.2016.03.005

23. Stamenkovic, V. R.; Mun, B. S.; Mayrhofer, K. J. J.; Ross, P. N.; Markovic, N. M. J. Am. Chem. Soc. 2006, 128, 8813-8819. doi:10.1021/ja0600476
24. Capelo, A.; Esteves, M. A.; de Sá, A. I.; Silva, R. A.; Cangueiro, L.; Almeida, A.; Vilar, R.; Rangel, C. M. Int. J. Hydrogen Energy 2016, 41, 12962-12975. doi:10.1016/j.ijhydene.2016.06.127

25. Hasché, F.; Oezaslan, M.; Strasser, P. Phys. Chem. Chem. Phys. 2010, 12, 15251-15258. doi:10.1039/c0cp00609b

26. Takei, C.; Kakinuma, K.; Kawashima, K.; Tashiro, K.; Watanabe, M.; Uchida, M. J. Power Sources 2016, 324, 729-737. doi:10.1016/j.jpowsour.2016.05.117

27. Baschuk, J. J.; Li, X. Int. J. Energy Res. 2001, 25, 695-713. doi:10.1002/er.713

28. Yan, W.-M.; Chu, H.-S.; Lu, M.-X.; Weng, F.-B.; Jung, G.-B.; Lee, C.-Y. J. Power Sources 2009, 188, 141-147. doi:10.1016/j.jpowsour.2008.11.107

29. Park, Y.-C.; Kakinuma, K.; Uchida, M.; Tryk, D. A.; Kamino, T.; Uchida, H.; Watanabe, M. Electrochim. Acta 2013, 91, 195-207. doi:10.1016/j.electacta.2012.12.082

30. Shao, Y.; Yin, G.; Gao, Y. J. Power Sources 2007, 171, 558-566. doi:10.1016/j.jpowsour.2007.07.004

31. Shao-Horn, Y.; Sheng, W. C.; Chen, S.; Ferreira, P. J.; Holby, E. F.; Morgan, D. Top. Catal. 2007, 46, 285-305. doi:10.1007/s11244-007-9000-0

32. Xie, J.; Wood, D. L., III; More, K. L.; Atanassov, P.; Borup, R. L. J. Electrochem. Soc. 2005, 152, A1011. doi:10.1149/1.1873492

33. Guterman, V. E.; Belenov, S. V.; Alekseenko, A. A.; Tabachkova, N. Y.; Volochaev, V. A. Russ. J. Electrochem. 2017, 53, 531-539. doi:10.1134/s1023193517050081

34. Moguchikh, E. A.; Alekseenko, A. A.; Guterman, V. E.; Novikovsky, N. M.; Tabachkova, N. Y.; Menshchikov, V. S. Russ. J. Electrochem. 2018, 54, 979-989. doi:10.1134/s102319351813030x

35. Zhang, Y.; Chen, S.; Wang, Y.; Ding, W.; Wu, R.; Li, L.; Qi, X.; Wei, Z. J. Power Sources 2015, 273, 62-69. doi:10.1016/j.jpowsour.2014.09.012

36. Guterman, V. E.; Belenov, S. V.; Alekseenko, A. A.; Lin, R.; Tabachkova, N. Y.; Safronenko, O. I. Electrocatalysis 2018, 9, 550-562. doi:10.1007/s12678-017-0451-1

37. Watanabe, M.; Yano, H.; Uchida, H.; Tryk, D. A. J. Electroanal. Chem. 2018, 819, 359-364. doi:10.1016/j.jelechem.2017.11.017

38. Dendooven, J.; Ramachandran, R. K.; Solano, E.; Kurttepeli, M.; Geerts, L.; Heremans, G.; Rongé, J.; Minjauw, M. M.; Dobbelaere, T.; Devloo-Casier, K.; Martens, J. A.; Vantomme, A.; Bals, S.; Portale, G.; Coati, A.; Detavernier, C. Nat. Commun. 2017, 8, 1074. doi:10.1038/s41467-017-01140-z

39. Yano, H.; Watanabe, M.; liyama, A.; Uchida, H. Nano Energy 2016, 29 , 323-333. doi:10.1016/j.nanoen.2016.02.016

40. Alinejad, S.; Quinson, J.; Schröder, J.; Kirkensgaard, J. J. K.; Arenz, M. ACS Catal. 2020, 10, 13040-13049. doi:10.1021/acscatal.0c03184

41. Favilla, P. C.; Acosta, J. J.; Schvezov, C. E.; Sercovich, D. J.; Collet-Lacoste, J. R. Chem. Eng. Sci. 2013, 101, 27-34. doi:10.1016/j.ces.2013.05.067

42. Gusev, A. I. Nanomaterials, nanostructures, nanotechnologies, 2nd ed.; Physmathlit: Moscow, Russia, 2009. 


\section{License and Terms}

This is an Open Access article under the terms of the Creative Commons Attribution License (https://creativecommons.org/licenses/by/4.0). Please note that the reuse, redistribution and reproduction in particular requires that the author(s) and source are credited and that individual graphics may be subject to special legal provisions.

The license is subject to the Beilstein Journal of Nanotechnology terms and conditions: (https://www.beilstein-journals.org/bjnano/terms)

The definitive version of this article is the electronic one which can be found at:

https://doi.org/10.3762/bjnano.12.49 